\title{
Conceitos Básicos da Matemática Financeira e sua Relação com os Conteúdos Tradicionais da Matemática
}

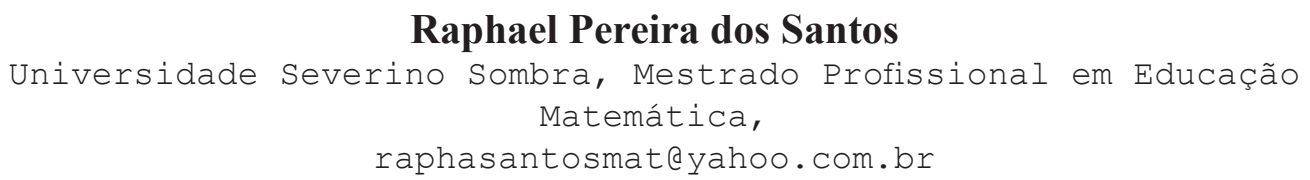

Raphael Pereira dos Santos

Universidade Severino Sombra, Mestrado Profissional em Educação Matemática, raphasantosmat@yahoo.com.br

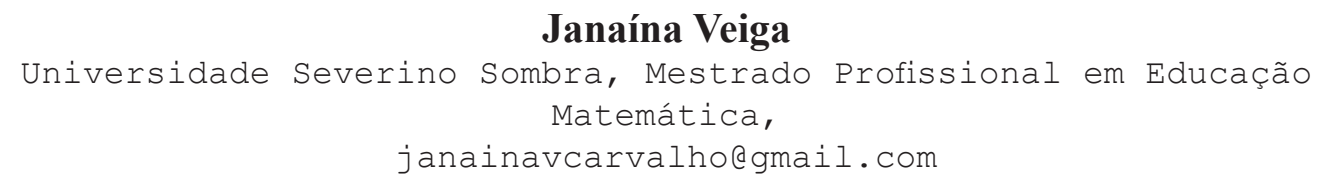

Ilydio Pereira de Sá

Universidade Severino Sombra, Mestrado Profissional em Educação Matemática, ilydio@gmail.com

Resumo: Neste artigo são apresentados os resultados parciais obtidos em um curso de formação continuada sobre Matemática Financeira para professores de Matemática do Ensino Médio, ministrado no decorrer da pesquisa objeto da dissertação de mestrado intitulada "Uma Proposta de Formação Continuada sobre Matemática Financeira para Professores de Matemática do Ensino Médio”. Partindo-se da hipótese de que um curso dessa natureza contribui para o desenvolvimento e a qualificação dos professores, objetivou-se mostrar aos docentes a relação dos conceitos básicos da Matemática Financeira com os conteúdos tradicionais da Matemática, ressaltando-se a importância da visualização e do uso de softwares educativos, os quais se constituem em ferramenta de fundamental importância no processo ensino-aprendizagem de conteúdos matemáticos, tais como juros simples e juros compostos, preço à vista e a prazo, amortização e capitalização. Apresenta-se, também, neste artigo, uma análise da forma como a Matemática Financeira é trabalhada em alguns livros didáticos para o ensino médio, assim como uma proposta de ensino de Matemática Financeira, na qual se mostra o que é o fluxo de caixa, com exemplos animados, utilizando uma ferramenta computacional, além de relacionar esse assunto a outros tópicos da Matemática. Fundamenta-se a pesquisa na perspectiva da Educação Matemática Crítica, por se acreditar que os conteúdos, as estratégias e a análise crítica provenientes da Matemática Financeira, muito mais que descrição de algoritmos, fórmulas e cálculos descontextualizados, favorecem uma educação matemática que estimula a investigação e o espírito crítico do aluno/cidadão.

Palavras-chave: Matemática financeira. Formação continuada de professores. Educação matemática crítica. Fluxo de caixa. Cidadania. 


\title{
Basic Concepts of Financial Mathematics and its Relationship with the Traditional Content of Mathematics
}

\begin{abstract}
This article presents the partial results obtained in a continuing education course on Financial Mathematics for mathematics teachers in high schools, taught during the research object of the dissertation entitled " $A$ Proposal for Continuing Education on Financial Mathematics for Teachers of Mathematics High School". Starting from the hypothesis that such a course contributes to the development and qualification of teachers, I aimed to show the relationship between teaching basic concepts of Financial Mathematics and the traditional content of mathematics, emphasizing the importance of visualization and the use of educational software, which consist of very important tool for teaching and learning mathematical content, such as simple interest and compound interest, price and term, amortization and capitalization. It appears, too, in this article, an analysis of how Financial Mathematics is elaborated in some textbooks for high school, as well as a teaching Financial Mathematics. It helps one define cash flow with animated examples, using a computational tool, and it relates this subject-matter with other topics of mathematics. It is based on research from the perspective of Critical Mathematics Education, because it is believed that the contents, strategies and critical analysis from the Financial Mathematics, much more than describing algorithms, formulas and decontextualized calculations, favor a mathematics education that fosters research and critique about the student/citizen.
\end{abstract}

Keywords: Financial mathematics. Continuing teacher education. Critical mathematics education. Cash flow. Citizenship.

\section{Introdução}

Ao ingressar no Programa de Mestrado Profissional em Educação Matemática da Universidade Severino Sombra, acreditando que o ensino de Matemática Financeira deveria esclarecer dúvidas, pretendia-se ajudar os alunos a evitar as jogadas de marketing de diversas empresas, quanto ao real valor dos produtos em transações comerciais e financeiras, principalmente em compras à vista e a prazo. Com a certeza de que isso poderia ser feito de modo contextualizado e dinâmico, passou-se a ter como objetivo a elaboração e preparação de um curso de formação continuada sobre Matemática Financeira para professores de Matemática do Ensino Médio. Tal curso visava a resgatar conteúdos de Matemática Financeira, assim como discutir problemas pertinentes a essa temática e demais questões com as quais as pessoas se deparam em seu dia a dia, trabalhando com a visualização - com animação do fluxo de caixa da operação - e com auxílio de uma ferramenta computacional como apoio ao processo ensino-aprendizagem (Santos, 2011).

O referido curso consistiu em uma análise de como a Matemática Financeira é trabalhada em alguns livros didáticos para o ensino médio, assim como no desenvolvimento de dois softwares, por meio dos quais o aluno visualizaria a dinâmica de um fluxo de caixa e o cálculo das parcelas de transações comerciais e financeiras. Para consecução de tais objetivos, partiu-se das seguintes hipóteses: 
- O uso de software específico, ao possibilitar a visualização de conceitos, contribui para um melhor aprendizado da Matemática.

- O ensino de conteúdos de Matemática Financeira, na educação básica, contribui para a formação cidadã de adolescentes e jovens.

- Uma abordagem contextualizada da Matemática Financeira facilita a compreensão e promove a autonomia e a criatividade dos alunos na resolução de situações que envolvam transações comerciais e financeiras.

Em seguida, definiram-se os objetivos da pesquisa:

- Demonstrar aos professores a relação dos conceitos básicos da Matemática Financeira com os conteúdos tradicionais da Matemática.

- Ressaltar a importância da visualização e de softwares educativos no processo ensinoaprendizagem.

Embora a Matemática Financeira seja uma ferramenta útil na análise de algumas alternativas de investimentos ou financiamentos de bens de consumo, revestindo-se de extrema importância para a formação cidadã, ela não vem sendo trabalhada de forma a que os alunos entendam suas aplicações e a relacionem a outros tópicos importantes da Matemática. Por outro lado, os livros didáticos, em sua maioria, continuam a apresentar exercícios baseados exclusivamente no uso de fórmulas, induzindo a soluções mecânicas, que não estimulam o raciocínio lógico.

Acredita-se, ainda, que, se a Matemática é um instrumento importantíssimo para tomada de decisões na vida de todas as pessoas e se tais decisões, para acontecerem, exigem acesso a conhecimentos que possibilitem intervenção no mundo (Freire 1996), então a Matemática Financeira é fundamental nesse processo de constituição de cidadãos críticos, a qual, por sua vez, associa-se a um comportamento ético (D'Ambrosio, 2002).

\section{A Matemática Financeira em Livros Didáticos para o Ensino Médio}

Muitos educadores matemáticos têm se preocupado em escrever sobre Matemática Financeira e discutir os assuntos a ela relacionados por diversos motivos: (i) relevância do tema na formação cidadã dos educandos; (ii) compõe a grade curricular do ensino médio; (iii) necessidade de ampliação de conhecimentos de alguns professores; (iv) abordagem diferente da praticada na maioria dos livros didáticos etc.

Segundo o "Guia de Livros Didáticos: PNLD 2010: Alfabetização Matemática e Matemática" (Brasil, 2009), cabe à escola e ao professor conduzir o processo ensinoaprendizagem, assim como proceder ao acompanhamento dos alunos. Para isso, o livro didático é um recurso de extrema importância e sua elaboração deve visar aos seguintes objetivos: 
- Favorecer a aquisição de conhecimentos socialmente relevantes.

- Propiciar o desenvolvimento de competências cognitivas que contribuam para aumentar a autonomia.

. Consolidar, ampliar, aprofundar e integrar os conhecimentos adquiridos.

- Auxiliar na autoavaliação da aprendizagem.

- Contribuir para a formação social e cultural e desenvolver a capacidade de convivência e de exercício da cidadania.

Sob esses aspectos, escolheram-se três coleções, de autores e editoras diferentes, consideradas as mais conhecidas e utilizadas por professores do ensino médio. Duas são coleções de três volumes: um livro para cada série do ensino médio; outra é apresentada em volume único. Cada coleção será analisada individualmente, no que se refere à abordagem da Matemática Financeira.

Em "Matemática: Contexto \& Aplicações" (Dante, 1999) (livro 1), há apenas um capítulo dedicado à Matemática Financeira. Nele, os tópicos são: introdução, números proporcionais, porcentagem, termos importantes de matemática financeira, juros simples, juros compostos e juros e funções.

Observa-se que o capítulo anterior ao de Matemática Financeira trata de progressões aritméticas e geométricas; entretanto, Dante (1999), ao discorrer sobre juros simples e compostos, não relaciona o assunto ao capítulo das progressões (Figura 1).

\section{Termos importantes de Matemática financeira}

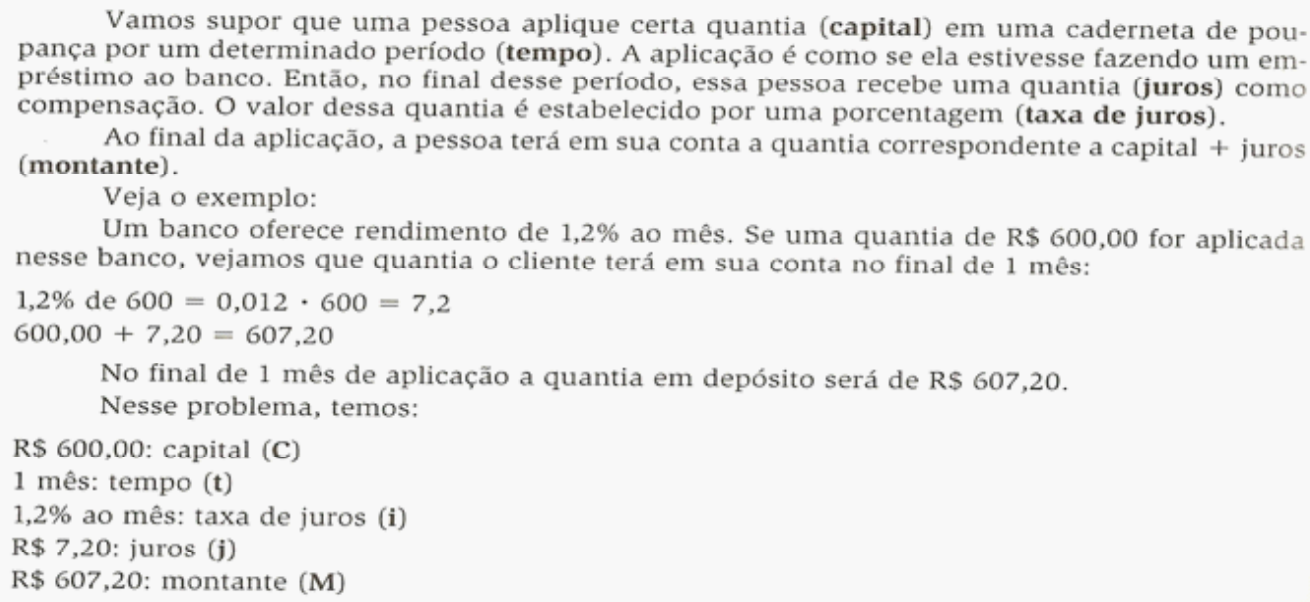

Vamos supor que uma pessoa aplique certa quantia (capital) em uma caderneta de poupança por um determinado período (tempo). A aplicação é como se ela estivesse fazendo um empréstimo ao banco. Então, no final desse perfodo, essa pessoa recebe uma quantia (juros) como compensação. O valor dessa quantia é estabelecido por uma porcentagem (taxa de juros). (montante). Ao final da aplicação, a pessoa terá em sua conta a quantia correspondente a capital + juros

Veja o exemplo:

Um banco oferece rendimento de $1,2 \%$ ao mês. Se uma quantia de $\mathrm{R} \$ 600,00$ for aplicada nesse banco, vejamos que quantia o cliente terá em sua conta no final de 1 mês:

$1,2 \%$ de $600=0,012 \cdot 600=7,2$

$600,00+7,20=607,20$

No final de 1 mês de aplicação a quantia em depósito será de RS 607,20.

Nesse problema, temos:

RS 600,00: capital (C)

1 mês: tempo (t)

$1,2 \%$ ao mês: taxa de juros (i)

R\$ 7,20: juros (j)

R\$ 607,20: montante (M)

\section{Juros simples}

Um capital aplicado à taxa de $2 \%$ de juros simples ao mês, durante 5 meses, rende $10 \%$ do capital no final desses 5 meses, ou seja, $5 \cdot 2 \%$.

Vejamos agora exercícios resolvidos sobre juros simples. Lembre-se de que a taxa e o tempo devem se referir à mesma unidade de tempo (\% ao mês e meses ou \% ao dia e dias, \% ao ano e anos, e assim por diante). 
É apenas nessa página que o autor define juros simples. Em seguida, são apresentados exercícios resolvidos com aplicação idêntica ao exemplo dado e o uso da fórmula de juros. Como se verifica, não há qualquer comentário sobre a existência de juros simples na vida dos cidadãos brasileiros. Para juros compostos, é mostrado um exemplo, no qual é deduzida a fórmula (Figura 2).

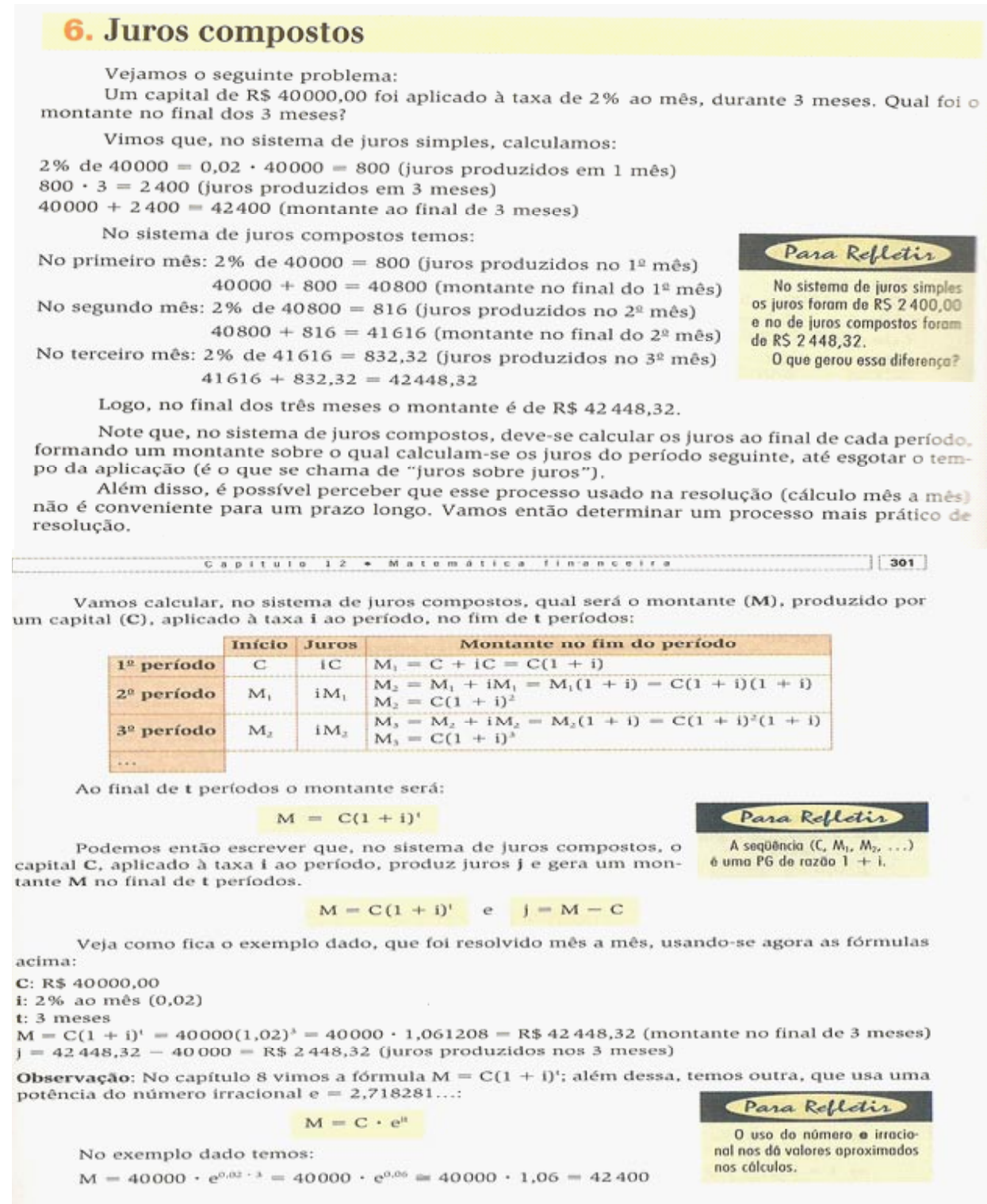

Figura 2. Abordagem de juros compostos (livro 1) Fonte: Dante (1999, p. 300-301) 
Em seguida, são apresentados exercícios resolvidos, com aplicação direta da fórmula. Observa-se que no quadro intitulado "Para Refletir", posicionado no canto inferior esquerdo da página, Dante [1999] informa que a sequência $\left(C, M_{1}, M_{2}, \ldots\right)$ é uma progressão geométrica de razão $1+\mathrm{i}$. Em nenhum momento, porém, o referido autor retorna a esse tópico nem é sugerida uma discussão para que os alunos trabalhem essa ideia.

No tópico 7 do referido livro, é tratado o tema "Juros e funções" (Figura 3).

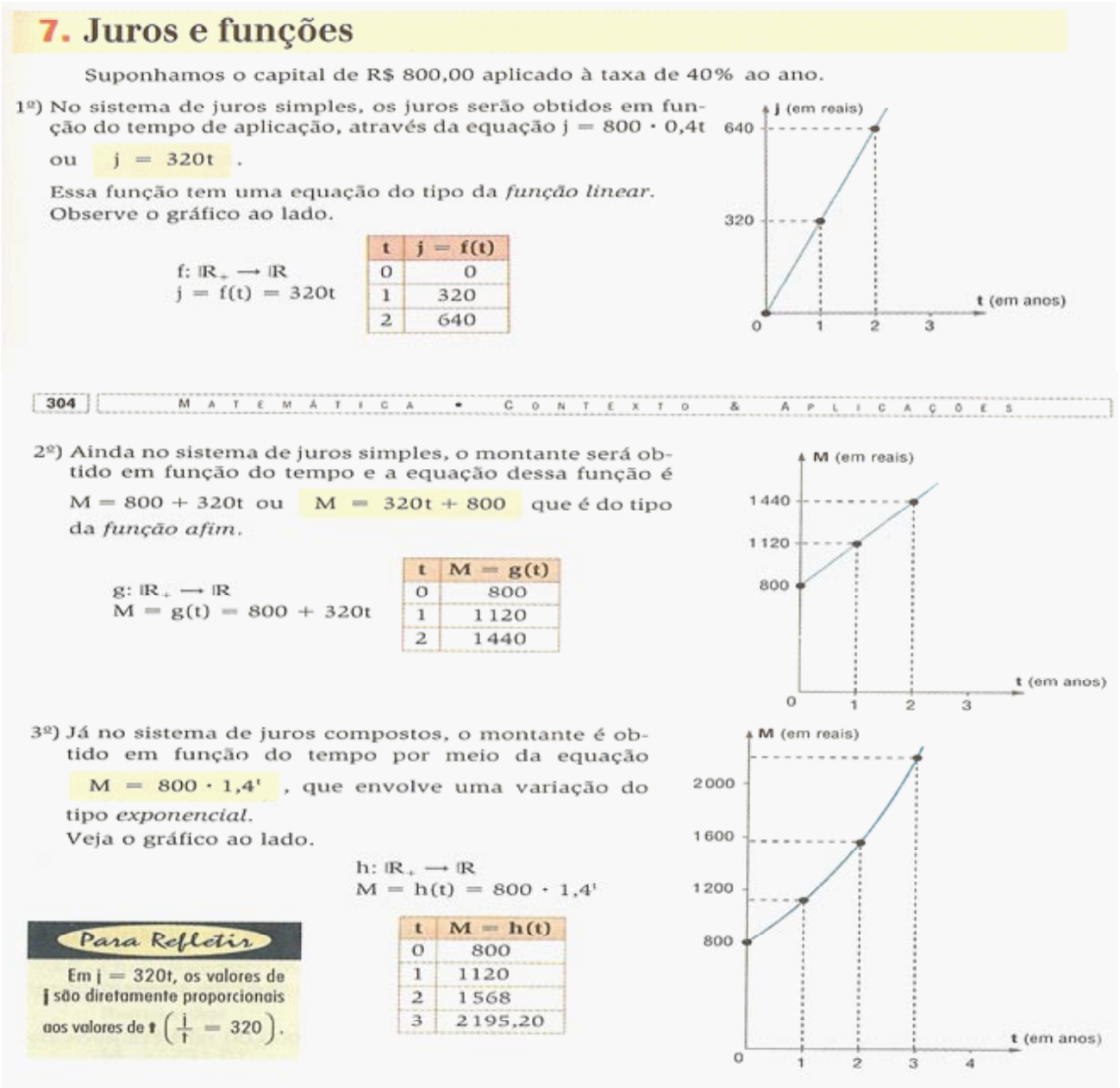

Figura 3 . Abordagem de juros compostos por funções (livro 1) Fonte: Dante (1999, p. 303-304)

Nesse item, a Matemática Financeira é relacionada a outros tópicos da Matemática. Há poucos exercícios de revisão e nenhum comentário sobre a relação desse tema com a realidade vivenciada por qualquer cidadão.

Em “Matemática” (Paiva, 1995) (livro 2), não há uma unidade específica para Matemática Financeira. No capítulo de progressões geométricas, o autor faz alguma relação entre estas e os juros compostos. Apenas com este exemplo, Paiva (1995) define juro composto: 
Aplicando $\mathrm{R} \$ 100.000,00$ durante três meses à taxa de juro de $10 \%$ ao mês, qual o juro composto produzido?

Em somente duas linhas Paiva (1995) se refere a juros simples, onde a taxa incide apenas sobre o capital inicial. $\mathrm{O}$ autor finaliza o tópico afirmando que, em países com inflação muito alta, essa prática não é utilizada por motivos óbvios.

Em seguida, Paiva (1995) deduz a fórmula do montante. Na sequência, apresenta exercícios resolvidos apenas para aplicação direta da fórmula (Figura 4).

\section{Fórmula para o cálculo do montante com juro composto e taxa constante}

Um capital $C$ é aplicado durante $n$ unidades de tempo à taxa $i$ por unidade de tempo. Calcule o mon tante acumulado ao final da aplicação.

A tabela a seguir mostra o montante acumulado no final de cada mês.

\begin{tabular}{c|c|c|c|}
\hline $\begin{array}{c}\text { Unidades } \\
\text { de tempo }\end{array}$ & Capital & Juro & Montante \\
\hline 1 & $C$ & $i C$ & $C+i C=C(1+i)$ \\
\hline 2 & $C(1+i)$ & $i C(1+i)$ & $C(1+i)+i C(1+i)=C(1+i)^{2}$ \\
\hline 3 & $C(1+i)^{2}$ & $i C(1+i)^{2}$ & $C(1+i)^{2}+i C(1+i)^{2}=C(1+i)^{3}$ \\
\hline 4 & $C(1+i)^{3}$ & $i C(1+i)^{3}$ & $C(1+i)^{3}+i C(1+i)^{3}=C(1+i)^{4}$ \\
\hline$\vdots$ & $\vdots$ & $\vdots$ & $\vdots$ \\
\hline
\end{tabular}

Observe que a coluna dos montantes apresenta a P.G.:

$$
\left(C(1+i), C(1+i)^{2}, C(1+i)^{3}, C(1+i)^{4}, \ldots\right) \text {, de razão } q=1+i \text {. }
$$

Ao final de $n$ unidades de tempo, o montante $M$ acumulado fica igual ao enésimo termo da P.G., isto é

$$
a_{n}=a_{1} q^{n-1} \Rightarrow M=C(1+i)(1+i)^{n-1} \quad \therefore M=C(1+i)^{n} .
$$

Chegamos então à fórmula do montante $M$ :

$$
M=C(1+i)^{n}
$$

Figura 4. Abordagem de juros compostos (livro 2)

Fonte: Paiva (1995, p. 56)

Da mesma forma, na sequência dos exercícios resolvidos, Paiva (1995) deduz a fórmula para o cálculo do montante com juro composto e taxa variável, procedendo ao cálculo dos montantes obtidos nos primeiros meses. Em seguida, são apresentados exercícios resolvidos para esse tópico, com a aplicação da fórmula deduzida. Poucos exercícios básicos e exercícios complementares finalizam o capítulo.

Assim como no livro 1, não há relação com outros tópicos da Matemática nem qualquer comentário, relacionando esse tema à realidade vivenciada por qualquer cidadão.

Em "Matemática para a Escola de Hoje" (Facchini, 2006) (livro 3), há um capítulo para a Matemática Financeira após os capítulos de progressões aritméticas e progressões geométricas. $\mathrm{O}$ autor inicia o capítulo com uma breve introdução à porcentagem. Em 
seguida, os juros simples são abordados a partir de um exemplo, define-se a fórmula para juros e são apresentados exercícios resolvidos e exercícios propostos para aplicação da fórmula.

Em seguida, é introduzido o assunto "Juros compostos”, utilizando-se a mesma abordagem (Figura 5).

\section{| Juros compostos}

Nas aplicações financeiras, de modo geral, é mais freqüente o uso de juros compostos. Neste caso, os rendimentos de cada período vão sendo somados ao capital e rendendo novos juros, e, no final da aplicação, o montante é maior.

No exemplo dado no item anterior, vimos que o capital de R\$ 2 000,00, aplicado a juros simples, durante 4 meses, à taxa de $3 \%$ ao mês, rende $\mathrm{R} \$ 240,00$ de juros.

Vamos, agora, resolver este mesmo problema, porém fazendo o cálculo com juros compostos, e, depois, comparar os resultados.

Fazendo o cálculo, mês a mês:

认 no final do $1^{\circ}$ período (1 mês), o montante será:

$100 \%$ de $R \$ 2000,00+3 \%$ de $R \$ 2000,00=103 \%$ de $R \$ 2000,00=$ $=1,03 \cdot \operatorname{R} \$ 2000,00=\operatorname{RS} 2060,00$

$\aleph$ no final do $2^{\circ}$ período ( 2 meses), o montante será:

$1,03 \cdot R \$ 2060,00=R \$ 2121,80$

no final do $3^{\circ}$ período ( 3 meses), o montante será:

$1,03 \cdot R \$ 2121,80=R \$ 2185,45$

认 no final do $4^{\circ}$ período (4 meses), o montante será:

$1,03 \cdot R \$ 2185,45=R \$ 2251,01$

Esse montante é, portanto, R\$11,01 maior que o do item anterior.

Figura 5. Abordagem de juros compostos (livro 3)

Fonte: Facchini (2006, p. 185-186)

Após o exemplo, são apresentados: definição da fórmula, exercícios resolvidos para sua aplicação e exercícios propostos com os mesmos propósitos.

Em seguida, é definida a fórmula de desconto, com os mesmos objetivos, com exercícios para aplicação da fórmula.

Em continuidade, valores financeiros equivalentes são propostos por meio de um exemplo para levar à formula, mas, nos três exercícios resolvidos que se seguem, é apresentado um esquema de pagamento para que os alunos possam visualizar. É a única parte do capítulo com esse tipo de proposta - visualização das parcelas. Em nosso entendimento, Facchini (2006) é o autor que mais se aproximou de uma abordagem relacionada ao cotidiano das pessoas (Figura 6). 
Temos que:

- valor equivalente à $1^{a}$ parcela $P$, na data $0=P$

- valor equivalente à $2^{a}$ parcela $P$, na data $0=\frac{P}{1+0,04}$

- valor equivalente à $3^{a}$ parcela $P$, na data $0=\frac{P}{(1+0,04)^{2}}$

Como as 3 parcelas saldaram a dívida, podemos escrever:

$$
\begin{aligned}
& P+\frac{P}{1+0,04}+\frac{P}{(1+0,04)^{2}}=950 \Rightarrow P \cdot 1,04^{2}+P \cdot 1,04+P=950 \cdot 1,04^{2} \Rightarrow \\
& \Rightarrow 3,1216 \cdot P=1027,52 \Rightarrow P=329,16 \\
& \text { Portanto, o valor de cada parcela é RS } 329,16 .
\end{aligned}
$$

R3 Um grande magazine oferece as 3 opções seguintes de pagamento para Maria Helena, na compra de um forno microondas:
a) à vista, com $15 \%$ de desconto;
b) em duas prestaçōes mensais iguais postecipadas, sem desconto, vencendo a $1^{*}$ um mês após a compra (as prestaçōes săo chamadas de postecipadas quando a $1^{12}$ prestação é paga um tempo depois da compra);
c) em três prestaçōes mensais iguais antecipadas e sem desconto.
Sabendo que o dinheiro vale para Maria Helena $5 \%$ ao mês, qual é a melhor opção para ela?

Como o enunciado não fornece o preço do bem, vamos supor que seja R\$ 420,00.

O pagamento à vista tem $15 \%$ de desconto, logo, o preço à vista seria R\$ 357,00 .

Temos, então, os esquemas possiveis abaixo:

a)<smiles></smiles>

b)

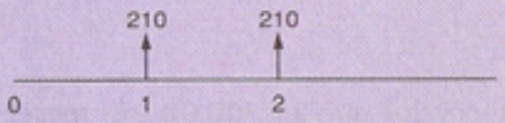

c) 140

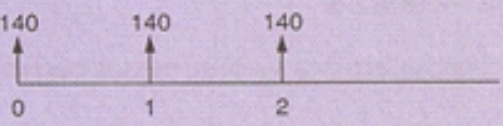

Calculando os valores na data 0 , temos:

a) RS 357,00

b) $\frac{210}{1+0,05}+\frac{210}{(1+0,05)^{2}}=$ RS 390,48

c) $140+\frac{140}{1+0,05}+\frac{140}{(1+0,05)^{2}}=$ RS 400,31

Comparando os valores, concluímos que a $1^{2}$ é a melhor das opçŏes.

Figura 6. Esquemas de pagamento (livro 3)

Fonte: Facchini (2006, p. 191-192)

Há, ainda, mais dois exercícios resolvidos, utilizando os esquemas de pagamentos possíveis.

Para encerrar o capítulo, taxas equivalentes são abordadas com exemplos - é deduzida a fórmula e aplicada diretamente nos exercícios resolvidos.

Embora tenhamos procedido a uma análise rápida sobre como os temas "juros simples" e "juros compostos" são abordados em livros didáticos para o ensino médio, constata-se que a aplicação de fórmulas é imediata e, salvo exceções, não é apresentada qualquer relação com outros tópicos da Matemática. 
Verifica-se que questões relativas ao valor do dinheiro no tempo quase sempre são preteridas, assim como praticamente não se trabalha a visualização para entendimento das parcelas, no caso de juros compostos.

Procedemos à comparação entre os três livros analisados, no que se refere aos assuntos considerados fundamentais para o tema estudado - juros simples e compostos (Quadro $1)$.

Quadro 1. Comparação entre os livros analisados sobre os conteúdos abordados

\begin{tabular}{|l|c|c|c|}
\hline \multicolumn{1}{|c|}{ Assunto Abordado } & Livro 1 & Livro 2 & Livro 3 \\
\hline Apresenta capítulo exclusivo para juros simples e juros compostos & Sim & Não & Sim \\
\hline Relaciona juros a funções & Sim & Não & Não \\
\hline Relaciona juros a progressões & Não & Sim & Não \\
\hline Apresenta algum tipo de esquema para visualização das parcelas & Não & Não & Sim \\
\hline Apresenta desafios contextualizados com questões do dia a dia & Não & Não & Sim \\
\hline Apresenta exercícios apenas com aplicação de fórmulas & Sim & Sim & Sim \\
\hline Apresenta questões com o valor do dinheiro no tempo & Não & Não & Sim \\
\hline
\end{tabular}

\section{Software para Juros Simples e Juros Compostos}

Com o objetivo de facilitar o processo ensino-aprendizagem de Matemática Financeira, decidimos pela construção de dois softwares, para facilitar aos alunos trabalhar questões como juros simples e juros compostos, valor das parcelas, progressões aritmética e geométrica.

\section{Tecnologia e Ferramenta Utilizadas no Desenvolvimento dos Softwares}

Segundo Evaristo (2002), basicamente há duas correntes de pensamento em relação ao processo ensino-aprendizagem de programação de computadores: uma defende o desenvolvimento da lógica de programação por meio de linguagem algorítmica, sem implementações em máquinas reais; outra defende o desenvolvimento da lógica de programação concomitantemente ao estudo de uma linguagem de programação, o que permite a implementação de exercícios e de programas em computadores.

A linguagem Pascal foi desenvolvida por Niklaus Wirth exatamente para os seguidores dessa segunda corrente, a qual possui comandos com sintaxes simples e semânticas facilmente compreensíveis. 
Além de facilitar o desenvolvimento da lógica de programação, Pascal é a linguagem básica do Delphi, um dos ambientes visuais para desenvolvimento de sistemas de computação mais usados em todo o mundo (aplicações desktop, multicamadas e cliente/servidor) e é compatível com os bancos de dados mais conhecidos do mercado. O Delphi apresenta as seguintes particularidades:

Visual: a definição da interface e até mesmo de parte da estrutura de um aplicativo Delphi é realizada com o auxílio de ferramentas visuais. Por exemplo, uma tela é criada com apenas um clique de um botão, selecionando-se a imagem na barra de ferramentas e clicando sobre a tela onde ela deve aparecer.

- Orientada a eventos: cada elemento de uma interface do aplicativo é capaz de capturar e associar ações a uma série de eventos.

- Compilada: a geração de código em linguagem de máquina acelera a execução dos aplicativos.

\section{Apresentação dos Softwares}

No software para juros simples e juros compostos, há quatro lacunas a serem preenchidas com valores (Capital ou Valor Presente; Número de Períodos; Taxa Mensal de Juros; Valor Futuro). $\mathrm{O}$ aluno atribuirá valores a apenas três dessas variáveis. $\mathrm{O}$ software calculará o valor da quarta variável, indicará o valor de todas as parcelas e fará uma representação dessas parcelas (Figuras 7 e 8).

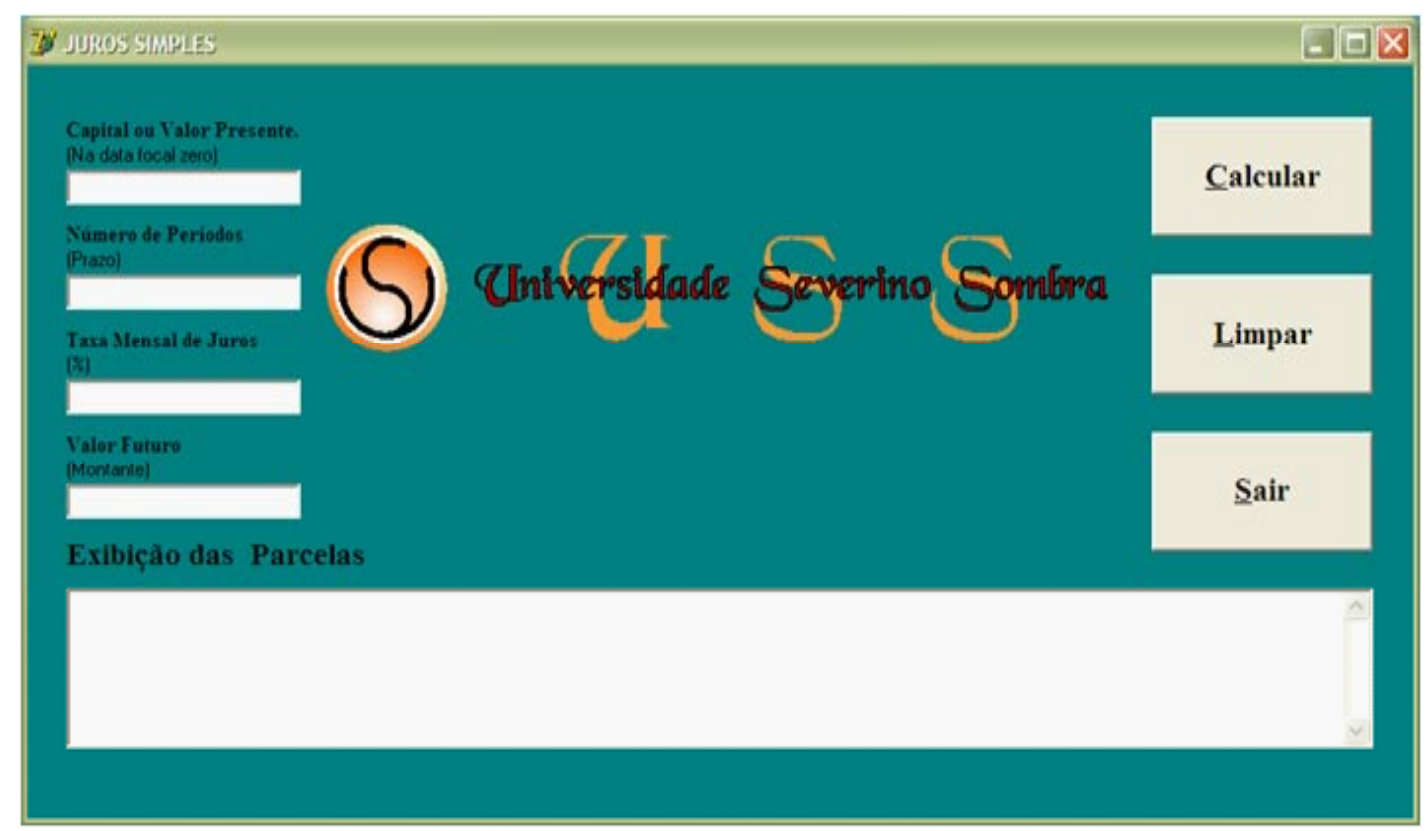

Figura 7. Interface do protótipo do software para juros simples 
Conceitos Básicos da Matemática Financeira e sua Relação com os Conteúdos Tradicionais da Matemática

Raphael Pereira dos Santos - Janaína Veiga - Ilydio Pereira de Sá

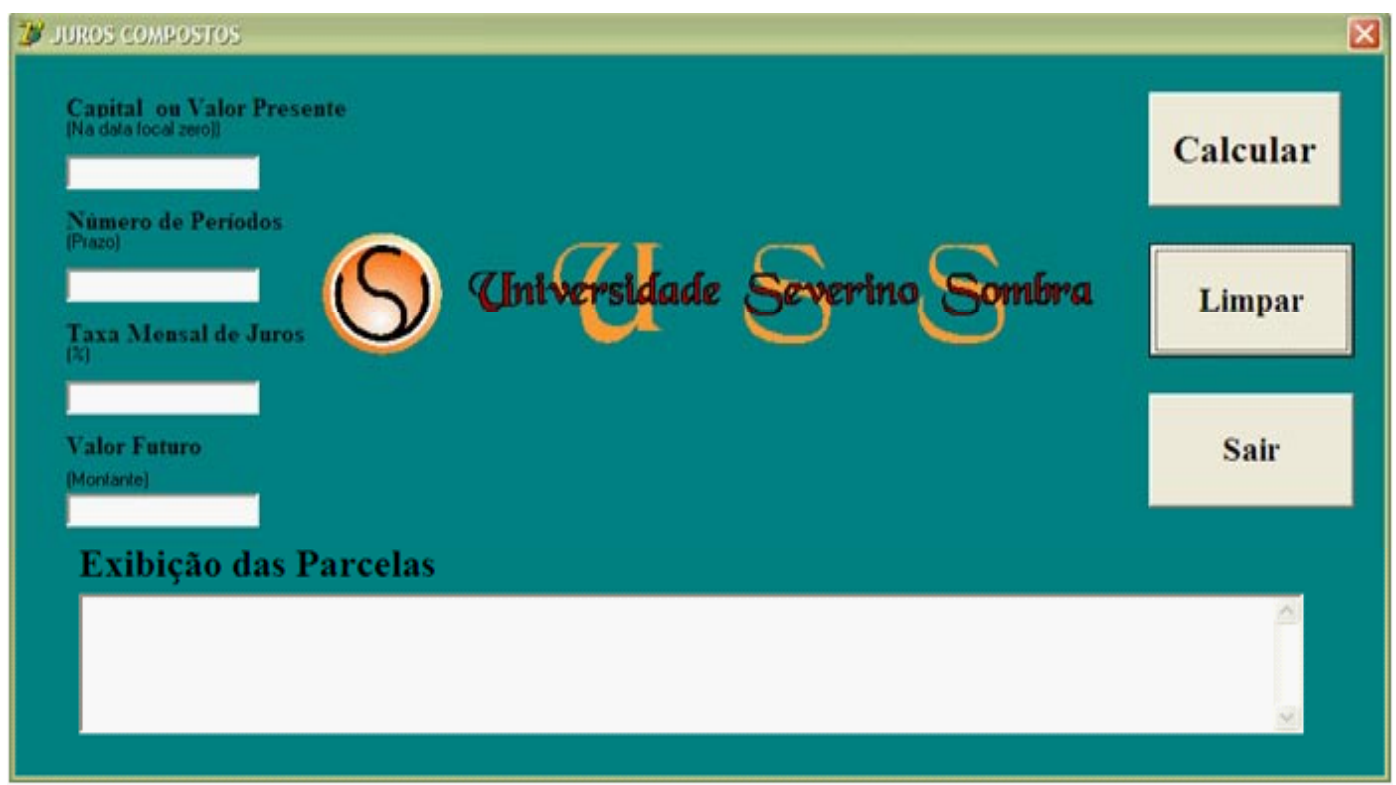

Figura 8. Interface do protótipo do software para juros compostos.

Nos juros simples, em cada período a taxa incide sobre o capital inicial, tornando o acréscimo constante. Já nos juros compostos, a cada período os juros são calculados sobre o montante no início desse período. Na prática, os juros aplicados pelas instituições financeiras são geralmente compostos. Por exemplo:

Se um capital de $\mathrm{R} \$ 100,00$ é aplicado por três meses, com uma taxa mensal de juros simples de $10 \%$, qual será o seu montante?

O aluno, ao preencher os valores no software de juros simples, obterá como resposta (Figura 9):

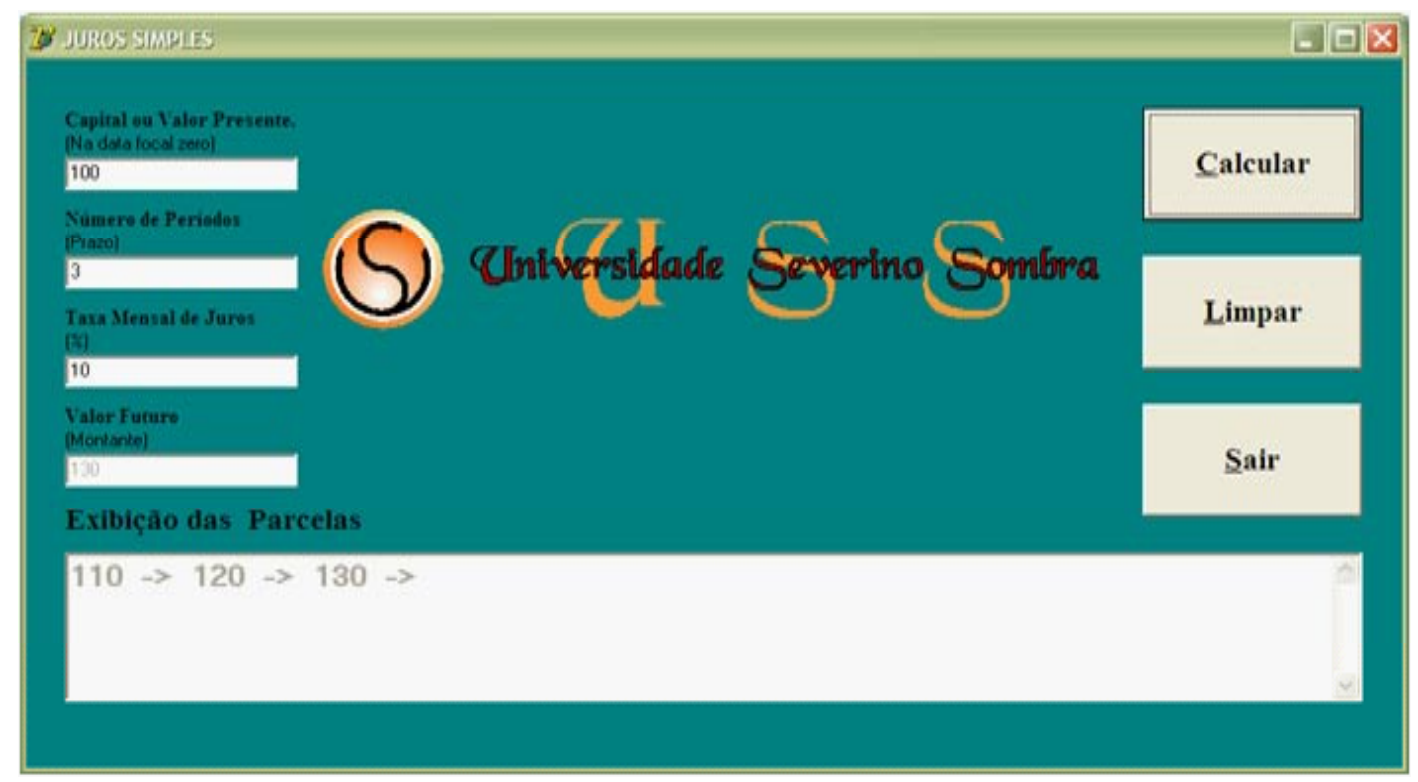

Figura 9. Utilização do software em um exemplo de juros simples 
No regime de juros compostos, os juros de cada período são calculados sobre o saldo do período anterior, que passará, então, a render novos juros. Juros compostos são também chamados de juros sobre juros ou juros capitalizados.

Observemos este exemplo:

Daniela tomou um empréstimo de $\mathrm{R} \$ 3.000,00$, a juros

compostos de $5 \%$ ao mês, com capitalização mensal.

Qual será a dívida de Daniela após seis meses?

O aluno, ao preencher os valores no software de juros compostos, obterá como resposta (Figura 10):

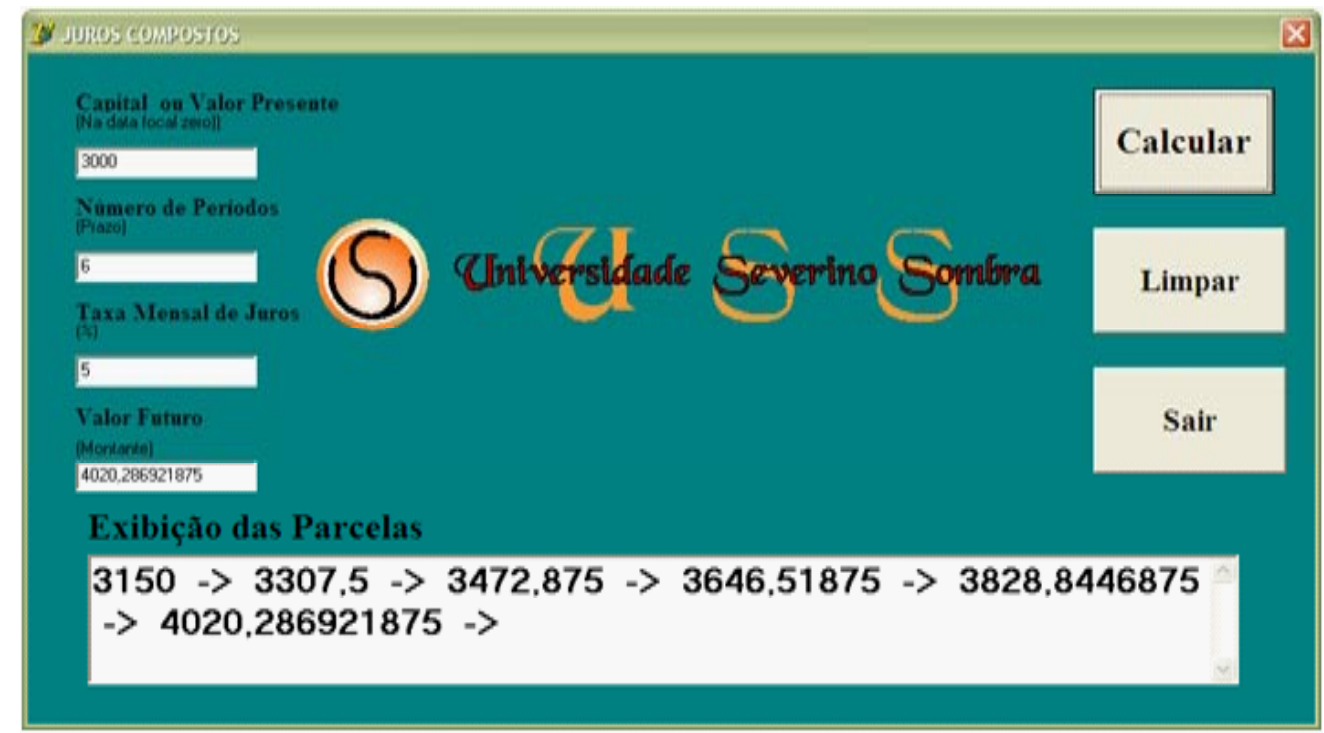

Figura 10. Utilização do software em um exemplo de juros compostos

\section{Fluxo de Caixa}

Segundo Sá (2005), fluxo de caixa de uma empresa ou de um cliente é o conjunto de entradas e saídas de dinheiro previsto para determinado período. $\mathrm{O}$ valor atual de um fluxo de caixa é a soma algébrica dos valores atuais das entradas (positivas) e das saídas (negativas).

Em uma análise de investimentos, compras a prazo e na Matemática Financeira em geral, o conceito de fluxo de caixa é de grande importância, pois, atualizando as entradas e saídas de dinheiro, é possível estimar se é ou não compensador determinado investimento (Figura 11). 


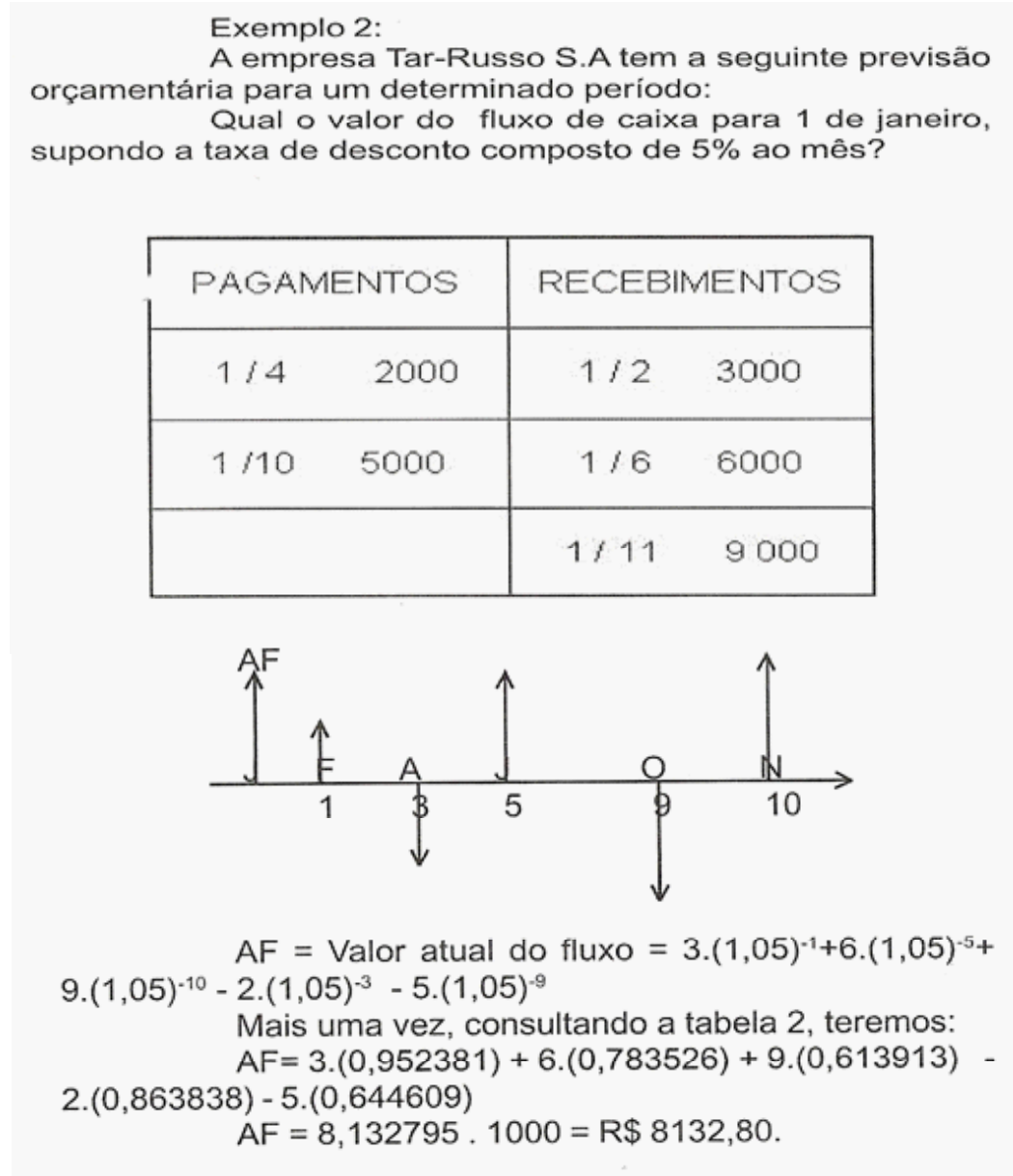

Figura 11. Exemplo de fluxo de caixa Fonte: Sá (2005, p. 92-93)

Caso as parcelas sejam iguais, podemos recorrer a tabelas financeiras prontas para amortizações e capitalizações compostas.

São estes os principais sistemas de amortização:

- Sistema de Pagamento Único: um único pagamento no final.

- Sistema de Pagamentos Variáveis: vários pagamentos diferenciados.

- Sistema Americano: pagamento no final, com juros calculados período a período.

- Sistema de Amortização Constante (SAC): a amortização da dívida é constante e igual em cada período.

. Sistema Francês ou Price (PRICE): os pagamentos (prestações) são iguais.

- Sistema de Amortização Misto (SAM): os pagamentos são as médias dos sistemas SAC e Price.

- Sistema Alemão: os juros são pagos antecipadamente com prestações iguais, exceto o primeiro pagamento, que corresponde aos juros cobrados no momento da operação. 
Em todos os sistemas de amortização, cada pagamento é a soma do valor amortizado e dos juros sobre o saldo devedor, isto é: Pagamento = Amortização + Juros .

\section{Animação com Auxílio de Ferramenta Computacional}

Serão apresentados alguns exemplos de utilização de uma ferramenta computacional, por meio da visualização das parcelas em um fluxo de caixa. Os exemplos foram exibidos em slides, durante o curso de formação continuada, e tiveram bastante aceitação por parte dos professores. Os exercícios contêm problemas em que se utiliza o valor do dinheiro no tempo, objetivando que o aluno desenvolva estratégias próprias para sua resolução (Figuras 12 e 13).

Vinícius tomou um empréstimo de $\mathrm{R} \$ 5.000,00$, a juros mensais de $5 \%$. Dois meses depois, ele pagou $\mathrm{R} \$$ 2.500,00; um mês após esse pagamento, liquidou seu débito. Qual o valor desse último pagamento?

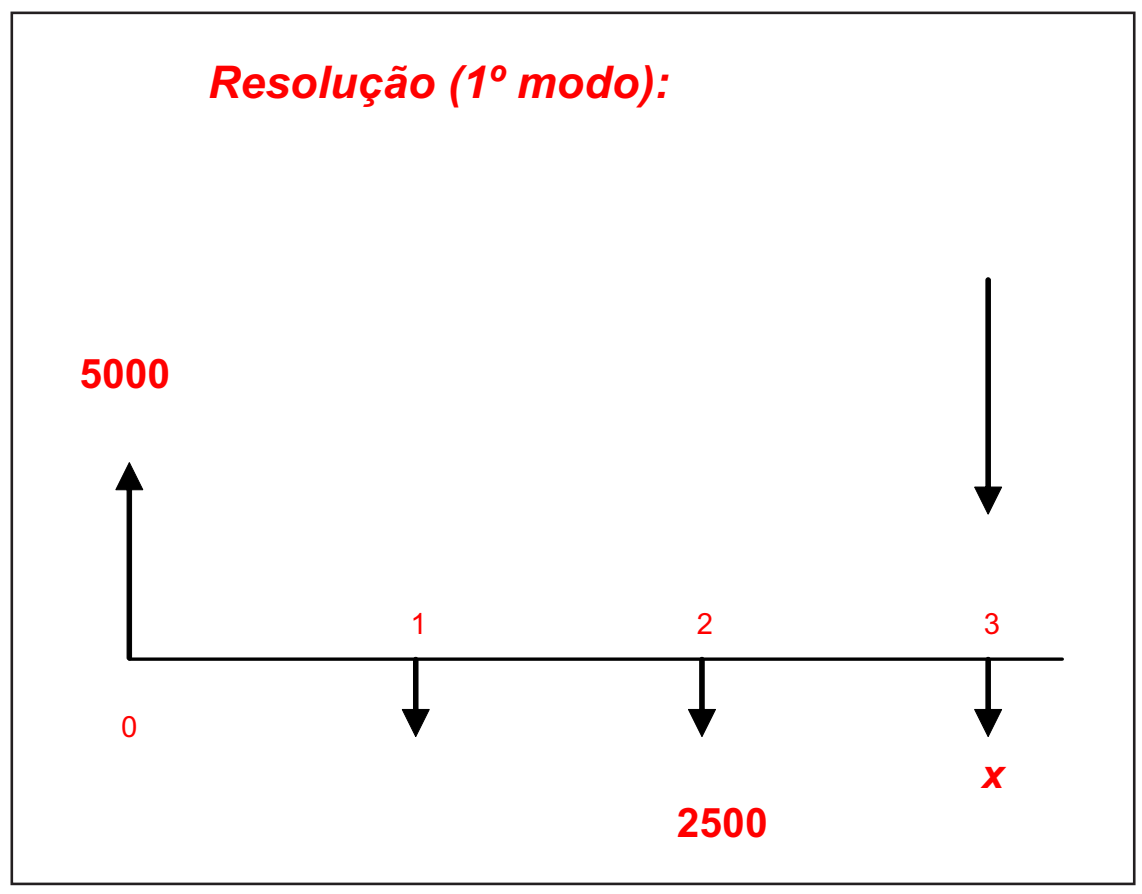

Figura 12. Primeiro slide apresentando resolução do exercício proposto Fonte: Modificado de Sá (2005) 
Conceitos Básicos da Matemática Financeira e sua Relação com os Conteúdos Tradicionais da Matemática

Raphael Pereira dos Santos - Janaína Veiga - Ilydio Pereira de Sá

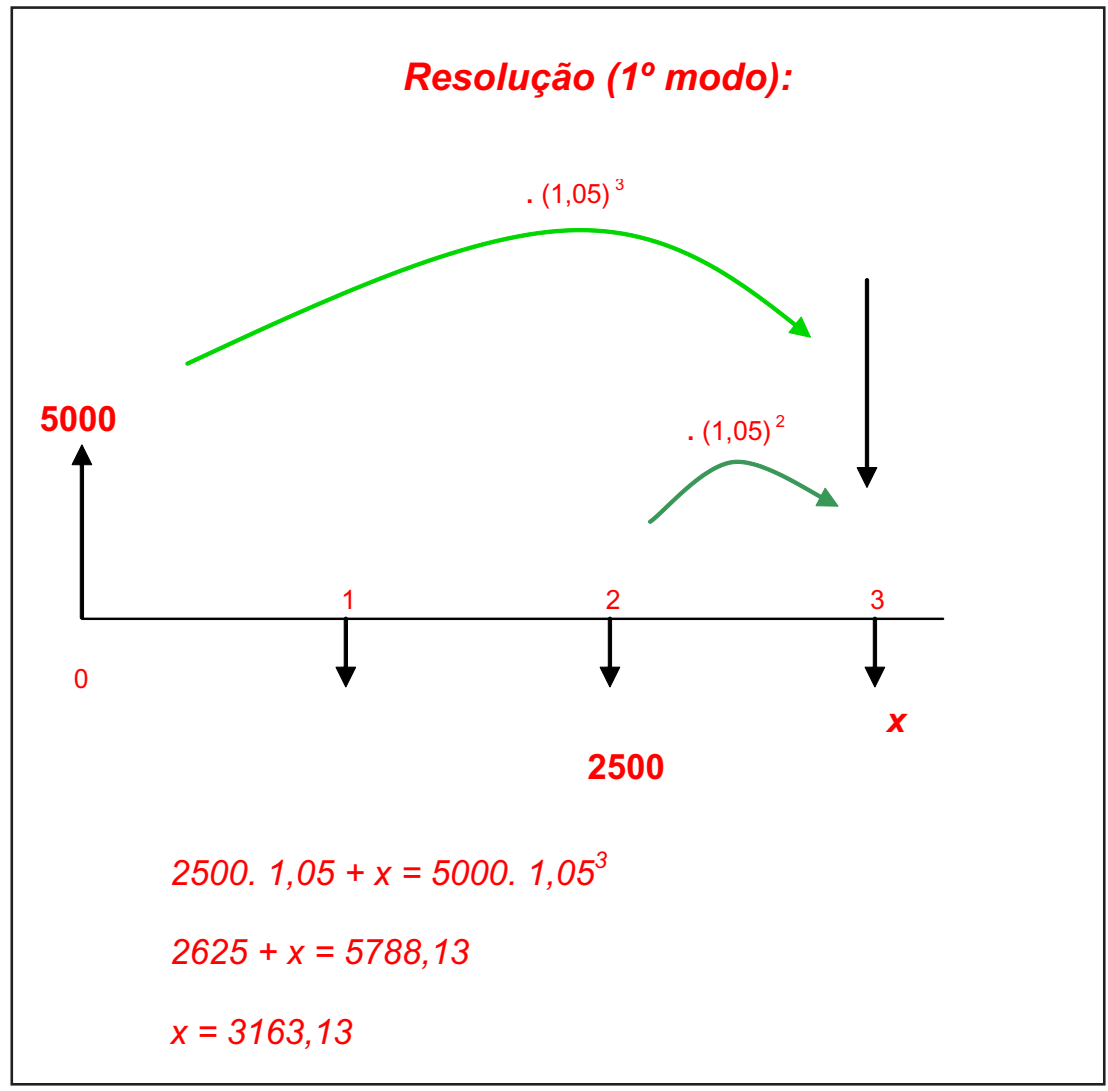

Figura 13. Segundo slide apresentando resolução do exercício proposto Fonte: Modificado de Sá (2005)

Analisemos uma segunda maneira de resolução (Figuras 14, 15 e 16).

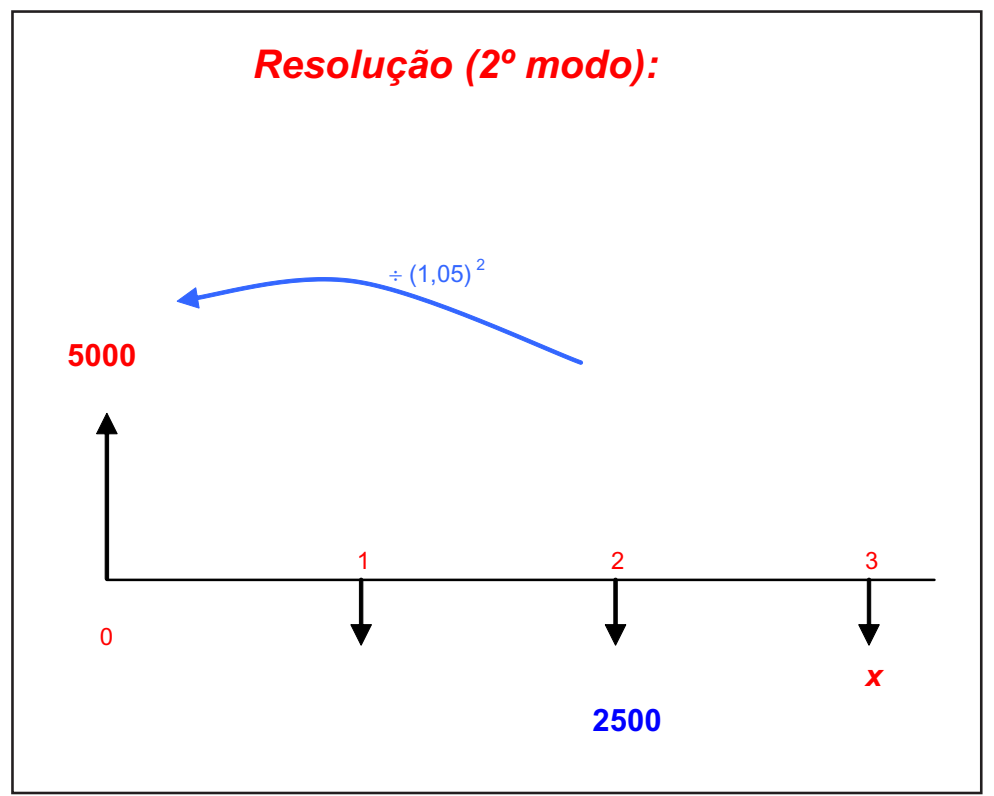

Figura 14. Primeiro slide apresentando outra resolução do exercício proposto Fonte: Modificado de Sá (2005) 


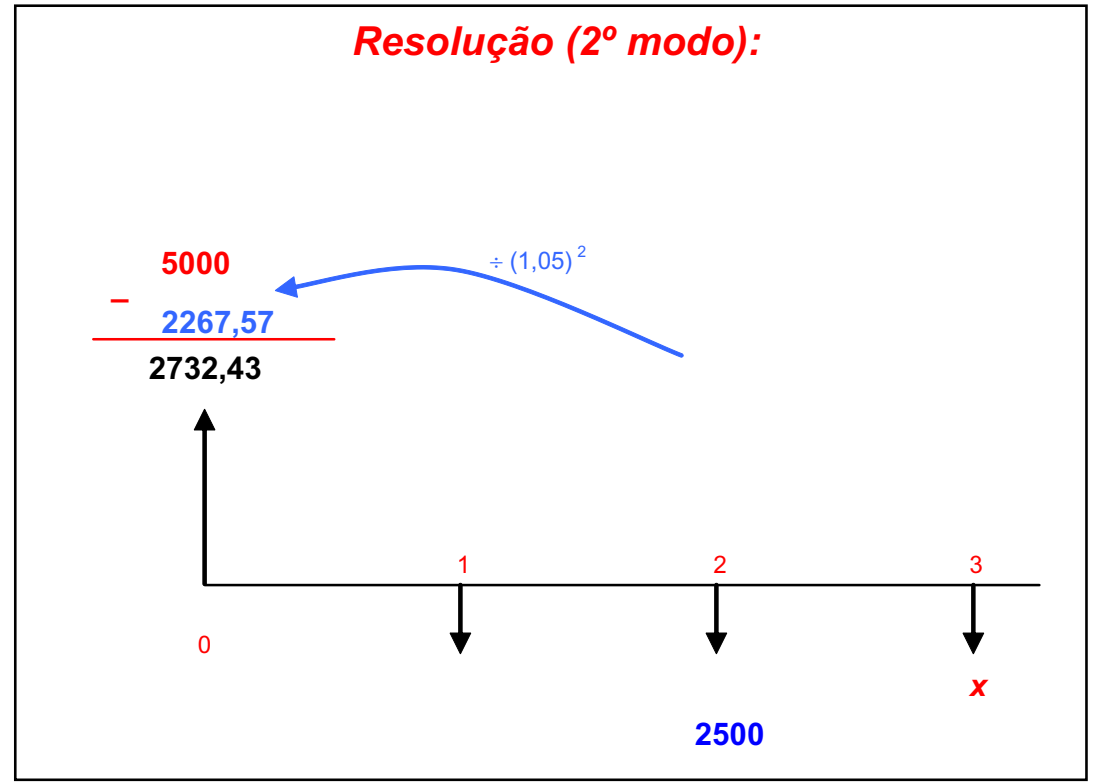

Figura 15. Segundo slide apresentando outra resolução do exercício proposto Fonte: Modificado de Sá (2005)

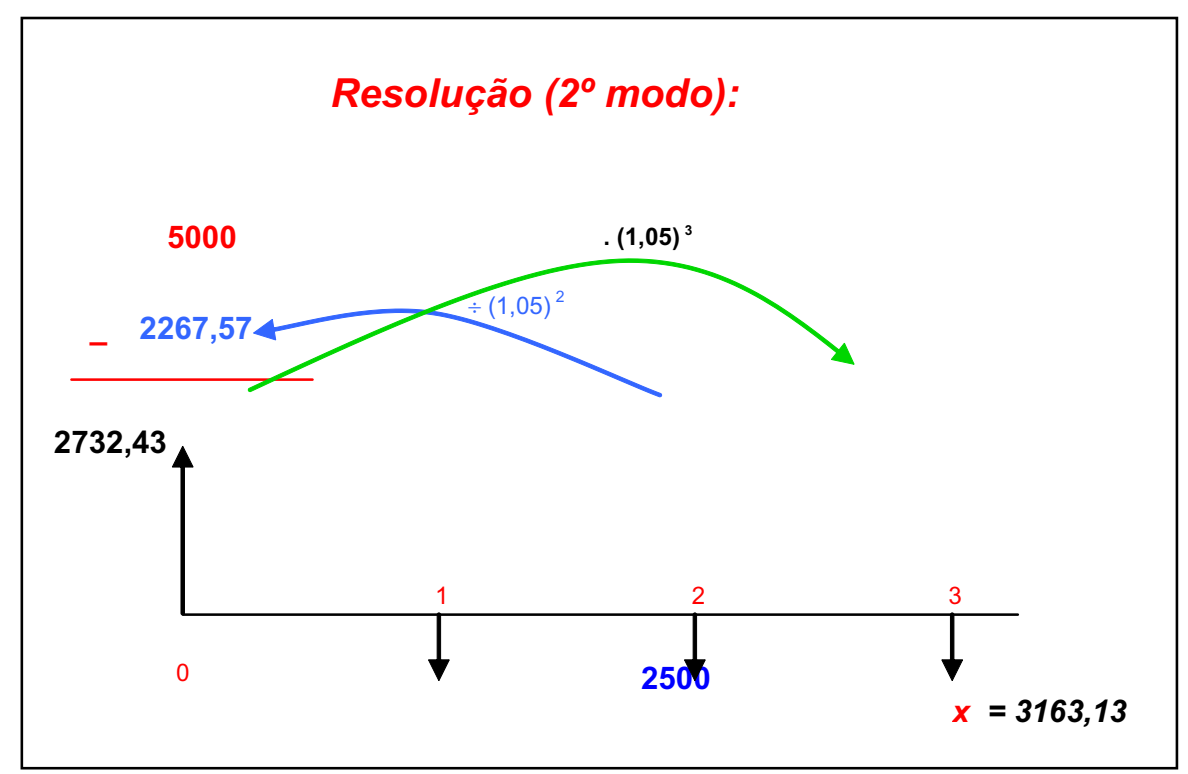

Figura 16. Segundo slide apresentando outra resolução do exercício proposto Fonte: Modificado de Sá (2005).

Segundo Novaes (2009), que idealizou o método de animação, este potencializa a diversidade de raciocínio ao fornecer subsídios para que o aluno crie sua própria abordagem para solucionar um problema. 


\section{Relações da Matemática Financeira com Outros Tópicos da Matemática}

No processo ensino-aprendizagem, a Matemática Financeira deve ser sempre relacionada a outros tópicos da Matemática, de modo a que os alunos a apreendam com maior facilidade. Como vimos nos exemplos anteriores, a ferramenta computacional auxilia uma maior associação dos conceitos da Matemática, além de facilitar o entendimento por meio da visualização.

Os alunos precisam ter claro que os juros simples são usados em poucas situações. Na maioria das vezes, as empresas/instituições financeiras trabalham com juros compostos. No regime de juros simples, os juros são calculados, em cada período, sobre o principal e não sobre o montante do período anterior. No regime de juros compostos, os montantes constituem uma progressão geométrica; nos juros simples, uma progressão aritmética (Figra 17).

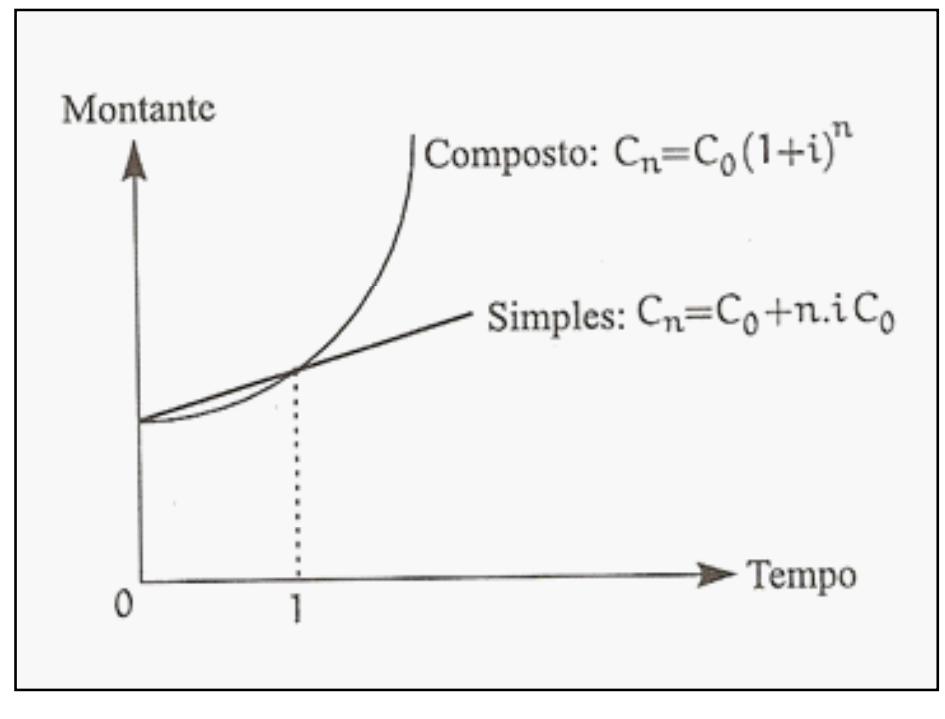

Figura 17. Gráfico comparativo entre juros simples e juros compostos

Esse gráfico mostra que os montantes a juros compostos são maiores que os montantes a juros simples. A exceção só ocorre se o prazo for menor que a unidade de tempo, onde juros simples dariam maior montante. Isso ocorre em juros de mora, cobrados por pequenos atrasos de pagamentos, ou em descontos bancários, quando os bancos subtraem uma parte de um título, cheque, letra, nota promissória etc., que é resgatada antes de seu vencimento.

No exemplo apresentado a seguir, utilizando uma ferramenta computacional, trabalhouse com a visualização no fluxo de caixa, relacionando a Matemática Financeira a outros tópicos da Matemática, em situações presentes no dia a dia de qualquer cidadão. Além deste, diversos exemplos foram apresentados (alguns extraídos de jornais, revistas e anúncios de grande circulação no estado) e discutidos no curso de formação continuada sobre Matemática Financeira para professores de Matemática do ensino médio (Figuras 18 a 22$)$. 
O Sr. Charles deposita em um banco, no fim de cada mês, durante cinco meses, a quantia de $R \$ 1.000,00$. Calcule o montante da renda acumulada, imediantamente após o último depósito, sabendo que o banco está pagando juros de $20 \%$ ao mês.

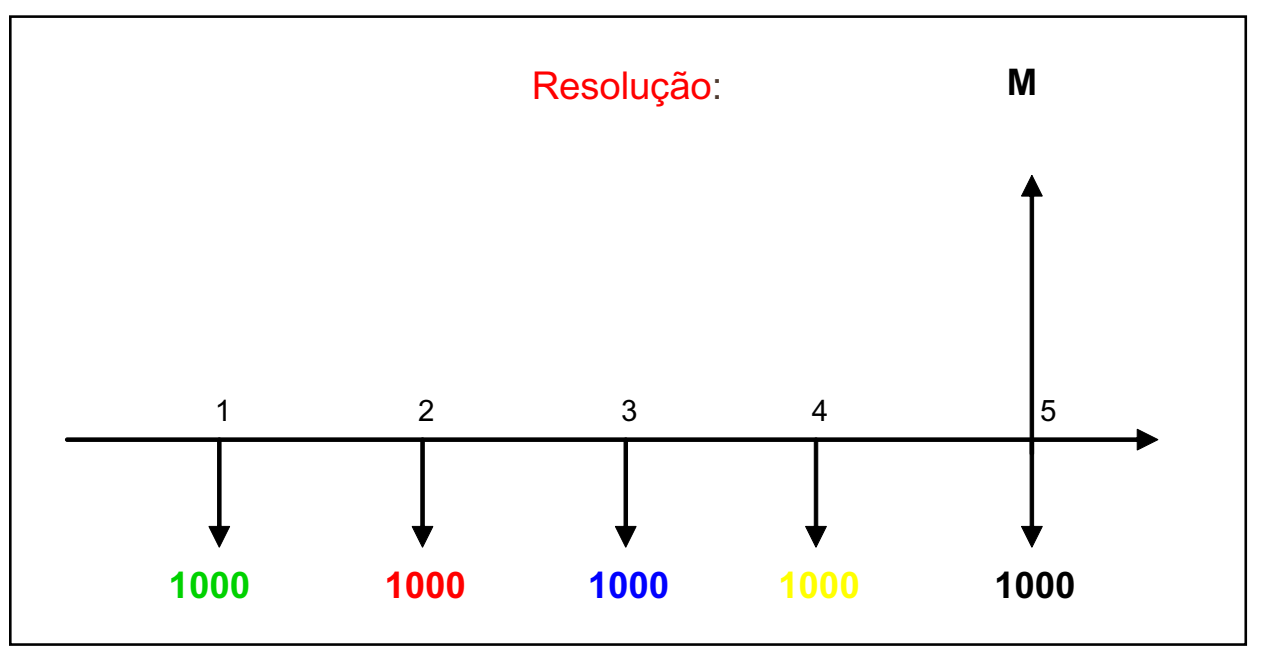

Figura 18. Primeiro slide apresentando resolução do exercício proposto Fonte: Modificado de Sá (2005)

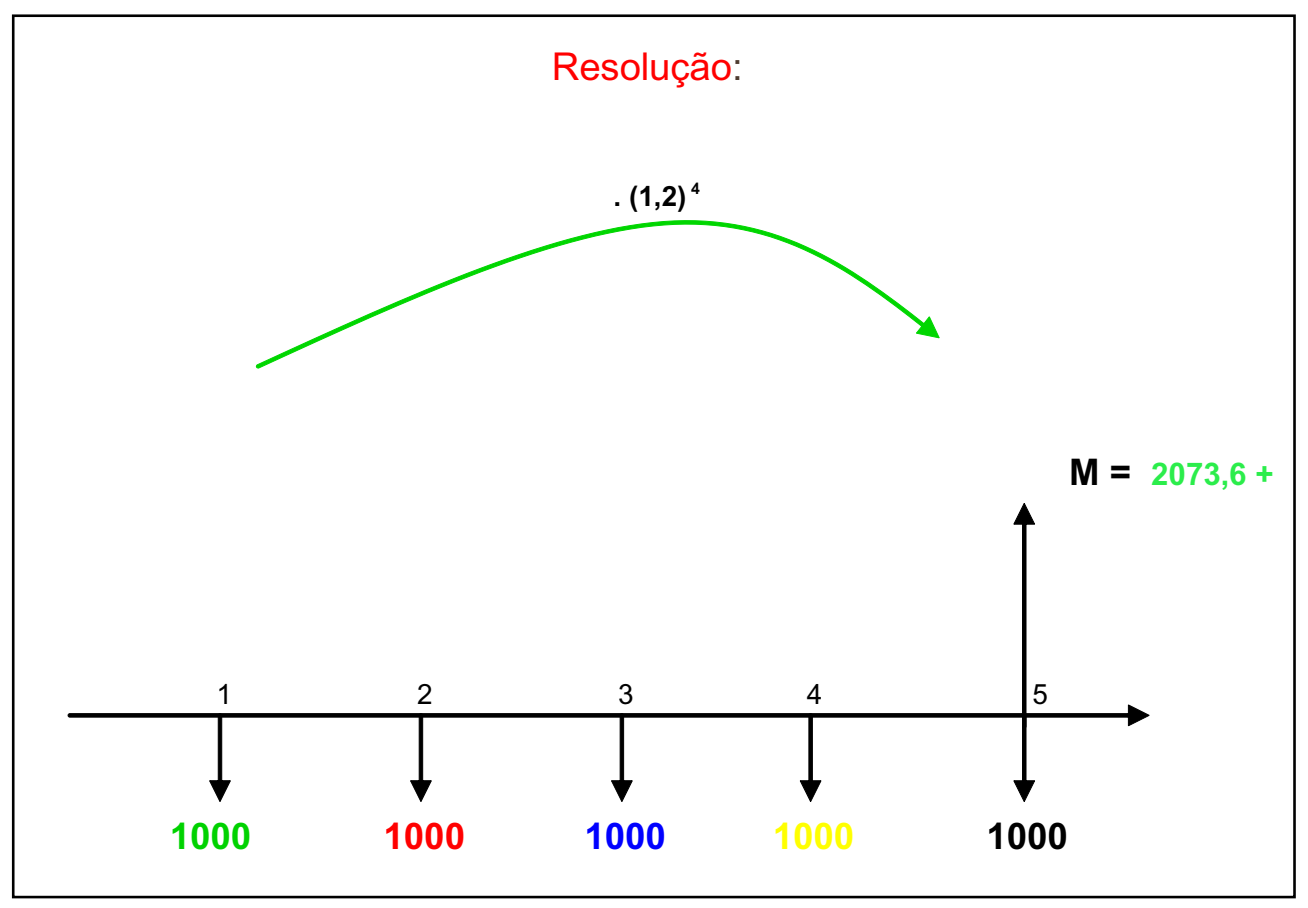

Figura 19. Segundo slide apresentando resolução do exercício proposto. Fonte: Modificado de Sá (2005) 


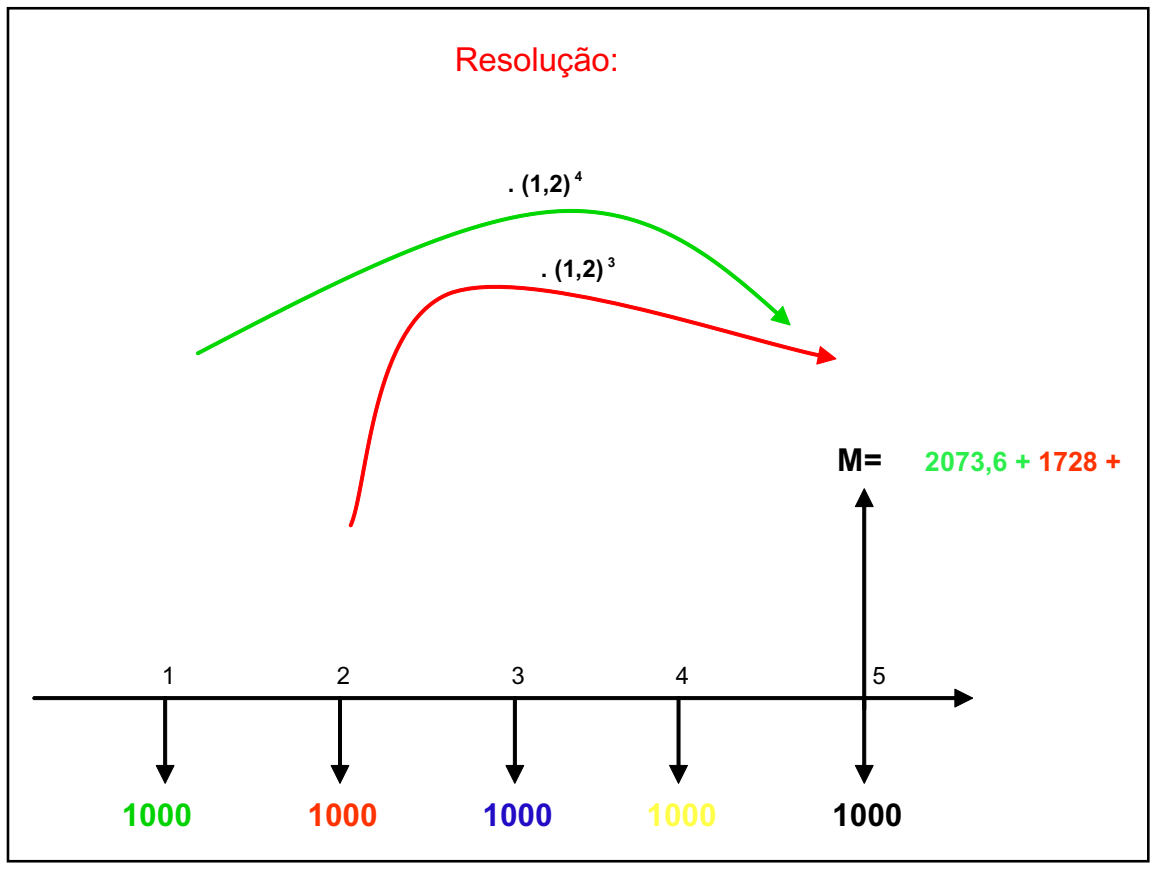

Figura 20. Terceiro slide apresentando resolução do exercício proposto Fonte: Modificado de Sá (2005)

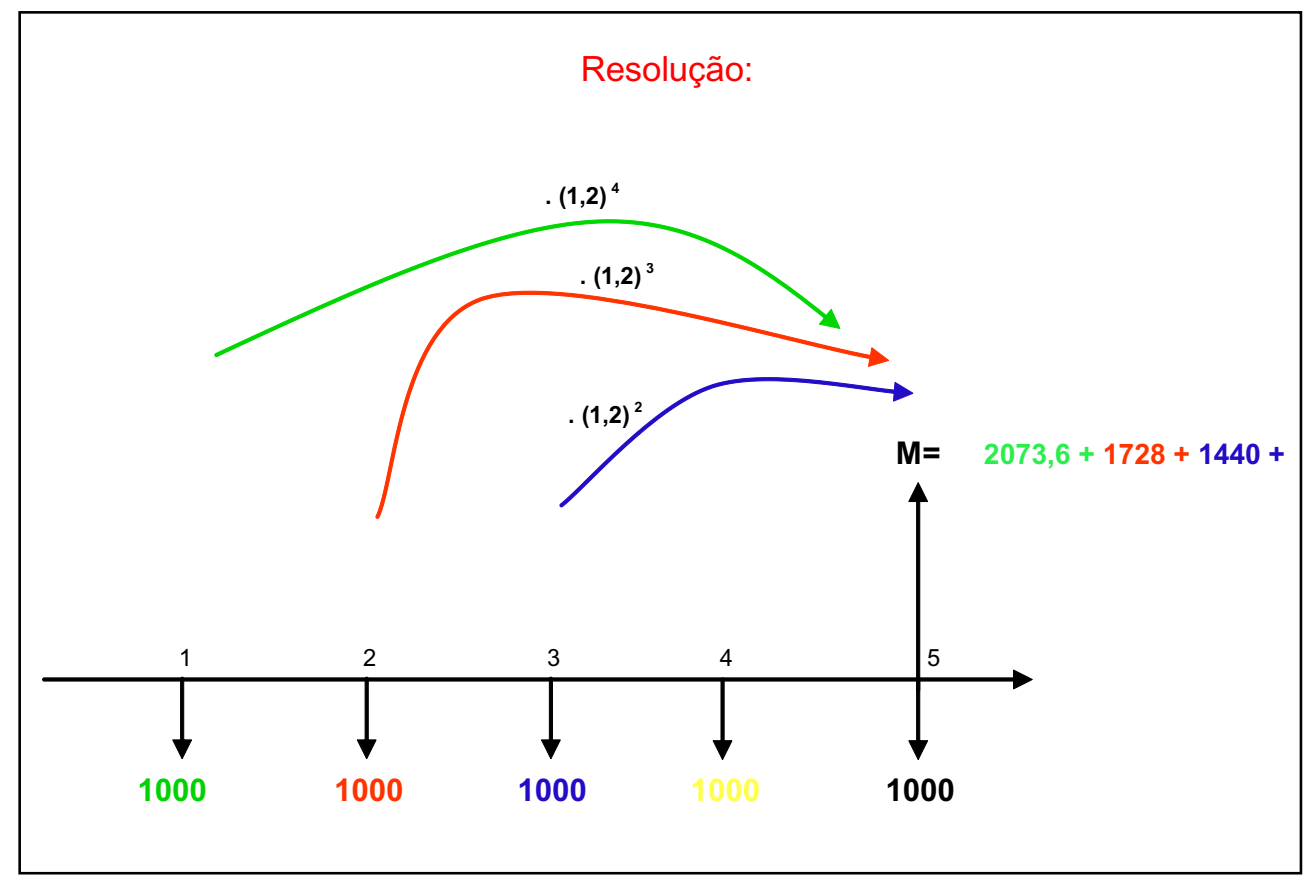

Figura 21. Quarto slide apresentando resolução do exercício proposto Fonte: Modificado de Sá (2005) 


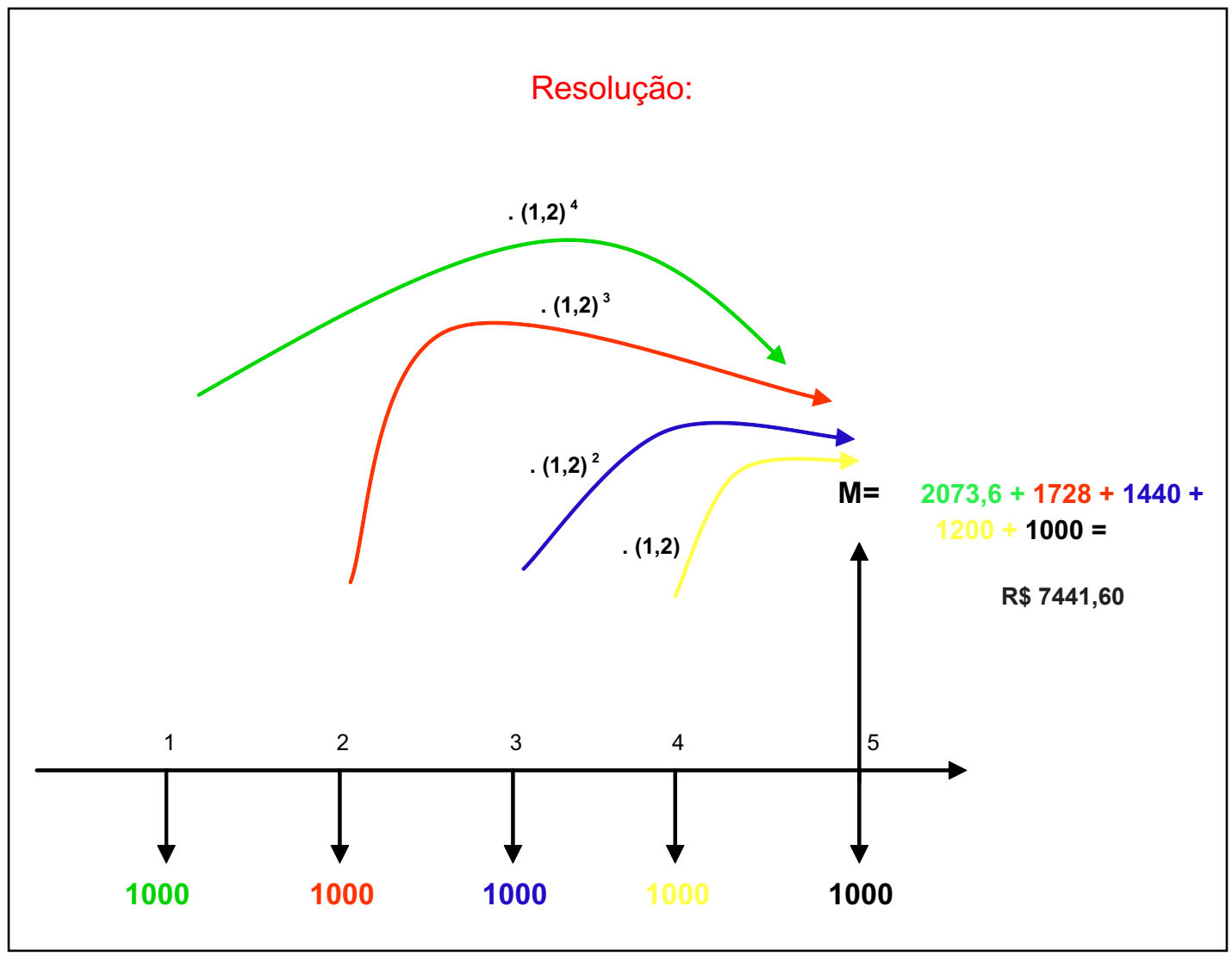

Figura22 . Quinto slide apresentando resolução do exercício proposto Fonte: Modificado de Sá (2005)

Como nos exemplos anteriores, pretendeu-se mostrar o valor do dinheiro no tempo. Da mesma forma, as sequências dos slides foram apresentadas parcela por parcela, até a data 5 (última data). Após a exibição, foram discutidas as relações desse tipo de exercício com outros tópicos da Matemática. Os professores chegaram à conclusão de que o montante final, resultado da soma dos montantes produzidos por cada uma das parcelas, poderia ser conseguido pela soma de uma progressão geométrica; decidiram, então, tentar resolver o problema dessa maneira até obterem o mesmo resultado.

\section{Considerações Finais}

Os alunos, de fato, ao concluírem o ensino médio, devem estar preparados para entender e tomar decisões quanto às questões relacionadas a transações comerciais e financeiras presentes no cotidiano e assuntos fundamentais do ensino médio, em particular a Matemática Financeira, contribuem para a formação cidadã do aluno. É seu direito ter acesso a uma formação digna no ensino médio. A Constituição Brasileira (Brasil, 1988) garante a todos os cidadãos o direito à educação, que é dever do Estado e da família, a qual deve visar ao desenvolvimento da pessoa e seu preparo para o exercício da cidadania.

Por outro lado, a criação de tecnologias voltadas para a educação vem se expandindo significativamente, ampliando o leque de ofertas de ferramentas de apoio ao ensino. A utilização de tais recursos, que viabilizam a possibilidade de um ensino com qualidade 
social, faz parte de políticas educacionais que visem à qualidade na formação do aluno.

A informática está presente no cotidiano da maioria das pessoas, em diversos níveis da sociedade, e sua utilização na escola é inevitável, cabendo aos alunos seu domínio como direito de cidadania. Precisamos, na condição de professores, promover o uso do computador como apoio ao processo ensino-aprendizagem, bem como desenvolver técnicas para facilitar a construção de conceitos.

Constatamos, durante a realização do curso ministrado a professores de Matemática do ensino médio, que a visualização, por meio de uma ferramenta computacional, para ensinar conteúdos de Matemática Financeira, além de facilitar o entendimento desses tópicos, permite o desenvolvimento de maneiras próprias na resolução de problemas comuns presentes no cotidiano.

Mas, para atingir esses objetivos, o professor precisa estar preparado para lecionar os conteúdos de forma contextualizada, e a Matemática Financeira, sendo um fator de contextualização de conteúdos, torna-se fundamental ao cidadão-aluno na aquisição de conhecimentos para o exercício de sua cidadania. Como um aluno, na sociedade em que vive, pode discutir questões políticas, econômicas, ambientais, sem esse suporte da Matemática?

Pretendemos, em um trabalho futuro, aperfeiçoar o software proposto para juros simples e juros compostos. Ao invés de calcular apenas o montante, o aluno poderá atribuir valores a qualquer das três variáveis das quatro existentes a serem preenchidas (capital ou valor presente, número de períodos, taxa mensal de juros e valor futuro). O software dará o valor à quarta variável, indicará o valor de todas as parcelas e fará uma representação visual dessas parcelas por meio do fluxo de caixa.

A animação executada no PowerPoint, para exibir as parcelas no fluxo de caixa, será incluída no software. Ou seja, ao preencher esses três valores, além de calcular o quarto valor, o software fará a visualização das parcelas para que o aluno possa fixar o que acontece com cada parcela e entender melhor os conteúdos de Matemática Financeira. 


\section{Referências}

Brasil (1988). Constituição da República Federativa do Brasil de 1988. Diário Oficial da União, Brasília, DF, 05 out. 1988, <http://www.planalto.gov.br/ccivil_03/Constituicao/ Constitui\%C3\%A7ao.htm>. Acesso em: 30 jan. 2010.

Brasil (2009). Guia de livros didáticos: PNLD 2010: alfabetização matemática e matemática, Brasília, Ministério da Educação, Secretaria de Educação Básica.

D’Ambrosio, U. (2002). Etnomatemática: elo entre as tradições e a modernidade, São Paulo, Autêntica.

Dante, L.R. (1999). Matemática: contexto \& aplicações, volume 1, Rio de Janeiro, Ática.

Evaristo, J. (2002). Aprendendo a programar programando na linguagem Pascal, Rio de Janeiro, Book Express.

Facchini, W. (2006). Matemática para a escola de hoje, São Paulo, FTD.

Freire, P. (1996). Pedagogia da autonomia: saberes necessários à prática educativa, São Paulo, Paz e Terra, 36. ed.

Novaes, R.C.N. (2009). Uma abordagem visual para o ensino de matemática financeira no ensino médio. Dissertação de mestrado apresentada ao Programa de Pós-Graduação em Ensino de Matemática da Universidade Federal do Rio de Janeiro, Rio de Janeiro.

Paiva, M. (1995). Matemática, São Paulo, Moderna.

Sá, I.P. de (2005). Matemática comercial e financeira (na educação básica) para educadores matemáticos, Rio de Janeiro, Sotese.

Santos, R.P. dos (2011). Uma proposta de formação continuada sobre matemática financeira para professores de matemática do ensino médio. Dissertação apresentada ao Programa de Pós-Graduação Stricto Sensu Mestrado Profissional em Educação Matemática da Universidade Severino Sombra, Vassouras, Rio de Janeiro. 